\title{
CONTEMPORARY DUAL MOBILITY HEAD PENETRATION AT FIVE YEARS: CONCERN FOR THE ADDITIONAL CONVEX BEARING SURFACE?
}

\author{
Evan R. Deckard, BS ${ }^{1}$ \\ Khalid A. Azzam, MD ${ }^{1,2}$ \\ R. Michael Meneghini, MD ${ }^{1,2}$ \\ ${ }^{1}$ Indiana University Health Physicians Orthopedics \& Sports Medicine, IU Health Saxony \\ Hospital, 13100 East $136^{\text {th }}$ Street, Suite 2000, Fishers, IN 46037 \\ ${ }^{2}$ Indiana University School of Medicine, Department of Orthopaedic Surgery, $1120 \mathrm{~W}$. \\ Michigan Street, Room 600, Indianapolis, IN 46202
}

Corresponding Author:

R. Michael Meneghini, MD

Indiana University Health Physicians Orthopedics and Sports Medicine Indiana University School of Medicine, Department of Orthopaedic Surgery 13100 East $136^{\text {th }}$ Street

Suite 2000

Fishers, IN, USA 46037

Phone: 317-688-5980

Email: rmeneghi@iuhealth.org

This is the author's manuscript of the article published in final edited form as:

Deckard, E. R., Azzam, K. A., \& Meneghini, R. M. (2018). Contemporary Dual Mobility Head Penetration at Five Years: Concern for the Additional Convex Bearing Surface? The Journal of Arthroplasty. https://doi.org/10.1016/i.arth.2018.02.061 


\section{CONTEMPORARY DUAL MOBILITY HEAD PENETRATION AT FIVE YEARS: CONCERN FOR THE ADDITIONAL CONVEX BEARING SURFACE?}

\section{Abstract}

Background: Dual mobility (DM) bearings are increasingly popular and second-generation designs contain highly cross-linked polyethylene (XLPE). The purpose of this study is to report head penetration rates in modern DM bearings.

Methods: A review of 63 consecutive DM bearings was performed. Radiographs were analyzed for head penetration using Martell methodology at regular postoperative intervals.

Results: 34 DM bearings were analyzed. Mean linear head penetration was $1.59 \mathrm{~mm} /$ year at oneyear, $1.07 \mathrm{~mm} /$ year at two-years, and $0.27 \mathrm{~mm} /$ year at five-years following an exponential regression model $\left(\mathrm{R}^{2}=0.999\right)$. Mean volumetric wear was $783 \mathrm{~mm}^{3} /$ year at one-year, 555 $\mathrm{mm}^{3}$ /year at two-years, and $104 \mathrm{~mm}^{3} /$ year at five-years following an exponential regression model $\left(\mathrm{R}^{2}=0.986\right)$.

Conclusion: Initial head penetration of DM bearings are larger than contemporary XLPE bearings; however, rates approach steady-state after two-years, analogous to traditional bearings. The larger "bedding in" head penetration may be due to the additional convex bearing surface, creating two surfaces for deformation/wear.

Keywords: Dual-mobility, total hip arthroplasty, bearing wear, femoral head penetration, highly cross-linked polyethylene 


\section{Introduction}

Total hip arthroplasty (THA) is one of the most successful medical procedures in the last century. However, the incidence of dislocation following THA has been reported up to $3.1 \%$ in primary and $8.4 \%$ in revision THA, [1] and remains a leading cause of revision THA with $32.4 \%$ of revisions being performed for recurrent instability and dislocation.[2, 3]

Originally designed in 1974 by Professor Gilles Bousquet and Andre Rambert in an attempt to achieve the greatest range of motion (ROM) with the lowest wear rates, the first generation dual-mobility bearing design featured conventional ultra-high molecular weight polyethylene (UHMWPE). Second generation designs introduced in the U.S. utilize highly crosslinked polyethylene (XLPE), which report improved wear resistance compared to first generation UHMWPE.[4-7]

Since the FDA approval of the dual mobility design in 2009, it has become increasingly popular in the United States for revision THA and patients at high risk for instability. Although the dual mobility design has been reported to reduce THA complications due to instability for the overwhelming majority of patients,[8-12] with intraprosthetic and extra-articular dislocation rates of $1.1 \%$ and $0.46 \%$ in primary THA and $0.3 \%$ and $2.2 \%$ in revision THA, respectively, [13] the wear and femoral head penetration due to plastic deformation associated with the dual mobility articulation remains unknown. The dual mobility design has two interfaces for wear, due to the outer convex surface and inner constrained bearing, compared to one fixed polyethylene liner in conventional THA. The purpose of this study is to report head penetration rates in modern dual-mobility bearings with highly cross-linked polyethylene out to five-years. 


\section{Methods \& Materials}

A retrospective review of 63 consecutive dual mobility bearings of one design (MDM, Stryker, Mahwah, NJ) was performed. All dual mobility bearings were utilized in high-risk primary $(n=11)$ or revision $(n=23)$ THA performed from March 2011 to January 2016. All patients received either a ceramic or cobalt-chromium femoral head in sizes $22.2 \mathrm{~mm}$ or $28 \mathrm{~mm}$. Of the 63 dual mobility liners, there was one dislocation six weeks postoperatively and two intraprosthetic dislocations (4.8\%) which dislocated at 1 month and 18 months postoperatively, respectively. The single dislocation was included in the analysis group as the head penetration rates were comparable to the rest of the cohort. The two intraprosthetic dislocations were excluded due to not being able to accurately measure head penetration on the radiographs. Standard anteroposterior (AP) radiographs were analyzed for linear and volumetric femoral head penetration using the Hip Analysis Suite software (Martell). Only AP radiographs were used for this study due to the "lateral" radiograph not being a true lateral view but rather a modified Lowenstein lateral radiograph. Optimal views of the femoral head, polyethylene liner and metal acetabular liner were used for head penetration analysis by adjusting and optimizing radiograph contrast in Synapse (PACS, Fujifilm Global). If any of the components could not be clearly identified on the radiograph, the data were excluded. The radiographs were then cropped out of Synapse and imported into ImageJ (imagej.nih.gov) to convert the image file formats from .$P N G$ to.$T I F F$ to be readable by Martell as per instructions and protocol.

The most recent radiograph (latest radiographic follow-up) was uploaded into Martell where the distal-most part of the ischial tuberosities were identified. The femoral head size and position were then identified. Next, the acetabular cup position was identified manually within the system. Next, the baseline radiograph (typically the four-week follow-up radiograph obtained 
in all patients) was uploaded and the process described was repeated for identifying the THA components. Following manual identification of the bony landmarks and dual mobility components in both radiographs, the Martell software calculated the linear head penetration (in $\mathrm{mm}$ ) indicated by a vector on the radiograph, the volumetric head penetration (in $\mathrm{mm}^{3}$ ), the acetabular cup inclination (in degrees) and acetabular cup rotation (in degrees). For each patient, linear and volumetric femoral head penetration, acetabular cup inclination and acetabular cup rotation data were collected between four-week and one-year radiographs with the four-week radiograph as the baseline. The same measurements were recorded between one-year and every year thereafter out to six-years post-op with the one-year radiograph as the baseline for all subsequent years to eliminate the possible bias of the potential bedding-in phenomenon that occurs during the first year and could subsequently elevate head penetration rates. Once the total head penetration (in $\mathrm{mm}$ ) was calculated by the Martell software, the in situ implantation time between the two radiographs of interest was divided into the total head penetration to obtain a linear head penetration rate (in $\mathrm{mm} / \mathrm{year}$ ). The same methodology was applied to the volumetric head penetration. The head penetration rates calculated at years 4 and 6 were removed from regression analysis due to low sample sizes $(n=2$ and 1, respectively), as these were "off years" of clinical follow-up and therefore, uncommon. Steady-state was operationally defined as when the difference between two subsequent head penetration rates were no longer statistically significant.

These data were recorded on three separate measurements at each time interval by one independent rater. Discrepancies greater than $2 \mathrm{~mm}$ between any of the three measurements were resolved. Average head penetration values between the three measurements less than zero were converted to a ' 0 ' value to prevent a false deflation of the overall head penetration rate by the 
negative number which is common practice in polyethylene wear studies reported in the peerreviewed literature.

Statistical Analysis

All statistical analyses were performed in Minitab 17 (State College, PA). Data were tested for normality with the Anderson-Darling (AD) test. Outliers were assessed with the appropriate form of Dixon's outlier test depending on the sample size at each time point.

Normally distributed continuous variables were analyzed with Student's two-sample t-test (t) and non-normally distributed continuous variables were compared with the Mann-Whitney (W) test adjusted for ties. Pearson's Chi-Square $\left(\mathrm{X}^{2}\right)$ test was used to test independence among categorical variables, with Fishers Exact test $p$ values reported for 2 x 2 contingency tables. A significance level of 0.05 was used for all statistical analyses.

\section{Results}

Of the 63 dual mobility bearing THAs, there were 29 exclusions: 2 were a different manufacturer, 21 were without a baseline one-year radiograph and 6 were excluded because the femoral head or acetabular cup could not be clearly identified for analysis in Martell.

\section{Demographics}

33 patients (34 hips) with a dual mobility bearing THA obtained minimum one-year follow-up and were analyzed. 50\% of the cohort were left hips, 53\% were females. Sixty-eight percent were complex revision cases as opposed to the other $32 \%$ that were complex primary THAs. The head penetration rates did not differ between primary and revision cases $(\mathrm{p} \geq 0.359)$. The cohort consisted of a mean age of $69.9 \pm 12.0$ years, mean height of $168.1 \pm 10.7 \mathrm{~cm}$, mean weight of $86.5 \pm 25.4 \mathrm{~kg}$ and median BMI of $28.0 \mathrm{~kg} / \mathrm{m}^{2}$. The cohort also consisted of 14 
ceramic and 20 cobalt-chromium femoral heads and three $22.2 \mathrm{~mm}$ femoral heads and thirty-one $28 \mathrm{~mm}$ femoral heads.

At one-year, mean acetabular component inclination and component anteversion was $54.6 \pm 7.9^{\circ}$ and $18.3 \pm 8.1^{\circ}$; respectively. Acetabular component inclination was greater than would be expected in a primary THA scenario, to the predominant use of this implant and bearing couple in revisions, where bone loss can create a realistic compromise between achieving adequate fixation and stability at the expense of the ideal implant inclination.

\section{Femoral Head Penetration Rates}

The mean linear head penetration rate was $1.59 \mathrm{~mm} /$ year the first year, $1.07 \mathrm{~mm} / \mathrm{year}$ at the second year and $0.27 \mathrm{~mm} /$ year at the five-year follow-up. The volumetric head penetration rates were $783 \mathrm{~mm}^{3} /$ year the first year, $555 \mathrm{~mm}^{3} /$ year at two-year follow-up and $104 \mathrm{~mm}^{3} /$ year at five-year follow-up. The linear (Figure 1) and volumetric (Figure 2) head penetration rates decreased following an exponential regression model, $\mathrm{R}^{2}=0.999$ and 0.986 ; respectively, which was the most mathematically intuitive for investigating the head penetration of a highly crosslinked polyethylene liner where the head penetration approaches zero.

The linear head penetration rates were trending different between one- and two-years $(\mathrm{p}=$ $0.114)$ but were not statistically different between two- and three-years $(p=0.190)$ and therefore, based on previous wear studies in the existing peer-reviewed literature, steady-state head penetration rate was considered to exist after two-years. These linear head penetration rates were not correlated with age at one, two, three or five years $(\mathrm{p} \geq 0.1)$. Further, there was no correlation between head penetration rates and UCLA Activity Level scores at any time point (one-year mean 4.3 SD 1.6, $\mathrm{p} \geq 0.409$ ). 
The linear head penetration rate model with a coefficient of determination $\left(\mathrm{R}^{2}\right)$ value of 0.999 allowed an accurate estimation of the linear penetration rate out further than the data were collected (Figure 3). At 15-years post-op, the estimated linear head penetration rate was 0.003 mm/year.

\section{Femoral Head Material Comparison}

The dual mobility bearing THAs were compared based on groups defined by the material of the femoral head (Figure 4). At two-years, the dual mobility bearings with ceramic femoral heads showed significantly lower linear head penetration rates at $0.37 \mathrm{~mm} /$ year compared to the cobalt-chrome penetration rate of $1.58 \mathrm{~mm} /$ year $(\mathrm{p}=0.015)$. The rates at one- and three-years were not significant; however, the total head penetration up to three-years when summed together favored the ceramic femoral heads (ceramic mean $2.66 \mathrm{~mm}$, range 0.0 to $5.0 \mathrm{~mm}$ vs cobalt-chromium mean $3.79 \mathrm{~mm}$, range 0.0 to $4.4 \mathrm{~mm} ; \mathrm{p} \leq 0.001$ ) suggesting there may be an advantage to using ceramic femoral heads in dual-mobility bearing constructs.

\section{Discussion}

Dual mobility bearings have seen increasing use since introduction into the US due to the larger effective head size and greater resistance to dislocation after THA, both in the primary and revision setting.[8-12,14-16] While this technology offers the benefit of increasing effective head size, the bearing is substantially different from conventional THA bearings in that a mobile polyethylene bearing articulates between a smaller femoral head and a cobalt-chrome acetabular liner, creating two surfaces for plastic deformation and wear. Subsequently, it is prudent that an assessment of the deformation and wear over time be performed in radiographic and retrieval studies. 
In our radiographic results reported here, measured head penetration rates of dual mobility bearings rates approach a steady-state after two-years $(\mathrm{p}=0.190$ between two-year and three-year linear rates), similar to behavior of traditional XLPE bearings. However, the early penetration rates of dual mobility bearings at one- and two-years exceed fixed bearing traditional THA bearing XLPE penetration rates by essentially twice the amount, despite the older, less active patient population of this series.[17, 18] Further, linear penetration rates did not correlate with age or activity level, but may be due to the smaller sample size and shorter term follow up. The five-year wear rates of sequentially annealed XLPE in conventional bearing THA has been reported at $0.11 \mathrm{~mm} /$ year after bedding in.[17] The five-year linear head penetration rate observed in this series of dual mobility bearings is also approximately double $(0.27 \mathrm{~mm} /$ year $)$. These consistent $2 \mathrm{X}$ penetration and wear rates of sequentially annealed highly-XLPE compared to the same material in a traditional THA bearing is observed in the initial beading-in period and the subsequent steady-state in vivo time period. Therefore, it is plausible the additional articulating convex surface could be causing elevated head penetration and/or wear rates in dual mobility systems compared to traditional THAs with a single articulating surface.

The head penetration rates for this series were substantially larger than reported wear rates by Adam and colleagues, who conducted a retrieval and surface analysis on dual mobility bearing polyethylene liners.[19] While Adam and colleagues reported substantially less linear and volumetric head penetration rates, the dual-mobility bearing liner material in their study was conventional UHMWPE and also utilized $22.2 \mathrm{~mm}$ diameter heads. This is in contrast to our dual-mobility construct reported here, where annealed highly cross-linked polyethylene liners and predominantly $28 \mathrm{~mm}$ heads were used. This comparison does suggest the possibility that 
the dual mobility cups composed of highly cross-linked polyethylene may undergo significant plastic deformation before reaching a steady-state wear rate.

The exponential regression model reported in this series of dual mobility bearings resembles long-term data reported by Rajpura and co-authors who followed conventional UHMPE out to 27 years.[18] However, despite demonstrating a nearly identical exponential regression head penetration model pattern as Rajpura, we report a substantially larger total linear head penetration of $4.15 \mathrm{~mm}$ at 5 -years in dual-mobility bearings, contrary to their mean total penetration of $0.41 \mathrm{~mm}$ at 27.5 years in conventional THA bearings.[18] Rajpura and co-authors report excellent 20 year wear rates in conventional polyethylene, and attribute the excellent wear behavior to the use of ceramic femoral heads.[18] Similarly, in our series of dual mobility bearings, the ceramic femoral heads show significantly lower total head penetration up to threeyears (Figure $4, p \leq 0.001$ ), suggesting there is an advantage to using ceramic femoral heads in dual mobility bearing liners.

Accuracy of the linear head penetration (Martell method) has been questioned in the literature for dual mobility bearings due to femoral heads occasionally being hidden behind the metal liner and therefore unable to accurately identify the femoral head's position and calculate the head penetration.[20] However, the radiographs of our series utilized modern digital software that was optimized by adjusting the contrast and image enhancement tools to ensure adequate visualization of the inner femoral head and outer metal acetabular liner. Further, the majority of bearings were adequately visualized and those for which the femoral head could not be identified were excluded from analysis. Pineau et al reported an RSA study that the accuracy for RSA was $0.034 \mathrm{~mm}$ (RMSE) and the Martell method reported accuracy is $0.033 \mathrm{~mm}$ (RMSE), deeming the 
Martell method to be sufficient for evaluating the head penetration in radiographs of sufficient quality.[21, 22]

This study has limitations. First, measurements were recorded from radiographs only. The temporal and mechanical property distribution between plastic deformation and true wear in dual mobility bearings with XLPE is unknown. The total head penetration is thought to be a combination of the true wear plus the plastic deformation that occurs up to two-years reported in the literature.[4, 23-25] Further, a controversial topic is the argument for[26-33] or against[3440] the effect of the polyethylene thickness on the plastic deformation and wear occurring in THA and conclusive evidence is lacking. Retrieval analyses would be required to confirm the amount of wear, the wear path characterization and the amount of plastic deformation in these more complex bearings to include both the convex and concave surfaces. Another limitation to the study is only using AP radiographs to evaluate volumetric head penetration. The volumetric head penetration of these cups was estimated from the linear head penetration. Accurate volumetric head penetration would have required lateral radiographs in combination with the AP view. One other limitation to this study was acetabular component inclination being elevated compared to the ideal angle of 40 degrees. The predominant use of this implant and bearing couple was used in revision cases, where bone loss can create a realistic compromise between achieving adequate fixation and stability at the expense of the ideal implant inclination. However, there are data to support that no adverse effect on wear has been observed with acetabular component malposition with highly-crosslinked polyethylene liner bearings. [38, 41] Another limitation to this study was the exclusion of nearly half the cases due to loss of followup after surgery. These exclusions could have introduced bias into the head penetration rates. Further follow-up on these cases is warranted to track long-term head penetration rates. Although 
UCLA Activity Level was not correlated with head penetration rates in this cohort, unknown elevated activity levels could explain the elevated penetration rates observed in this study although the patient cohort is older and less active for the majority of the cohort. Our data reveal some provocative results regarding both qualitative and quantitative information of femoral head penetration behavior in a modern dual mobility bearing that utilizes highly cross-linked polyethylene. The data suggest the dual mobility bearing has an initial head penetration period, followed by a steady-state wear in an exponential regression model over time. Further the magnitudes of head penetration and wear are substantially larger than those reported for highly cross-linked polyethylene in traditional THA fixed-bearing couples.

Therefore, caution should be exercised before adopting the dual mobility bearings in widespread use for routine THA patients without risk factors for instability until further studies are performed that encompass longer-term clinical follow-up and retrieval analyses. 
1. Mahomed NN, Barrett JA, Katz JN, Phillips CB, Losina E, Lew RA, Guadagnoli E, Harris

WH, Poss R, Baron JA. Rates and outcomes of primary and revision total hip replacement in the United States medicare population. The Journal of Bone and Joint Surgery American volume 85a(1): 27, 2003

2. Bozic KJ, Kurtz SM, Lau E, Ong K, Vail TP, Berry DJ. The epidemiology of revision total hip arthroplasty in the United States. J Bone Joint Surg Am 91(1): 128, 2009

3. Schairer WW, Sing DC, Vail TP, Bozic KJ. Causes and frequency of unplanned hospital readmission after total hip arthroplasty. Clin Orthop Relat Res 472(2): 464, 2014

4. Glyn-Jones S, McLardy-Smith P, Gill HS, Murray DW. The creep and wear of highly crosslinked polyethylene: a three-year randomised, controlled trial using radiostereometric analysis. J Bone Joint Surg Br 90(5): 556, 2008

5. Glyn-Jones S, Isaac S, Hauptfleisch J, McLardy-Smith P, Murray DW, Gill HS. Does Highly Cross-Linked Polyethylene Wear Less Than Conventional Polyethylene in Total Hip Arthroplasty?: A Double-Blind, Randomized, and Controlled Trial Using Roentgen

Stereophotogrammetric Analysis. The Journal of Arthroplasty 23(3): 337, 2008

6. Glyn-Jones S, Thomas GER, Garfjeld-Roberts P, Gundle R, Taylor A, McLardy-Smith P,

Murray DW. The John Charnley Award: Highly Crosslinked Polyethylene in Total Hip

Arthroplasty Decreases Long-term Wear: A Double-blind Randomized Trial. Clinical

Orthopaedics and Related Research® 473(2): 432, 2015 
8. Prudhon JL, Ferreira A, Verdier R. Dual mobility cup: dislocation rate and survivorship at ten years of follow-up. Int Orthop 37(12): 2345, 2013

9. Philippot R, Camilleri JP, Boyer B, Adam P, Farizon F. The use of a dual-articulation acetabular cup system to prevent dislocation after primary total hip arthroplasty: analysis of 384 cases at a mean follow-up of 15 years. Int Orthop 33(4): 927, 2009

10. De Martino I, Triantafyllopoulos GK, Sculco PK, Sculco TP. Dual mobility cups in total hip arthroplasty. World J Orthop 5(3): 180, 2014

11. Langlais FL, Ropars M, Gaucher F, Musset T, Chaix O. Dual mobility cemented cups have low dislocation rates in THA revisions. Clin Orthop Relat Res 466(2): 389, 2008

12. Guyen O, Pibarot V, Vaz G, Chevillotte C, Bejui-Hugues J. Use of a dual mobility socket to manage total hip arthroplasty instability. Clin Orthop Relat Res 467(2): 465, 2009

13. Darrith B, Courtney PM, Della Valle CJ. Outcomes of dual mobility components in total hip arthroplasty: a systematic review of the literature. The Bone \& Joint Journal 100-b(1): 11, 2018 14. Zagra L, Caboni E. Total hip arthroplasty instability treatment without dual mobility cups: brief overview and experience of other options. Int Orthop 41(3): 661, 2017

15. Rowan FE, Salvatore AJ, Lange JK, Westrich GH. Dual-Mobility vs Fixed-Bearing Total Hip Arthroplasty in Patients Under 55 Years of Age: A Single-Institution, Matched-Cohort Analysis. J Arthroplasty 32(10): 3076, 2017

16. Lange JK, Spiro SK, Westrich GH. Utilizing Dual Mobility Components for First-Time Revision Total Hip Arthroplasty for Instability. J Arthroplasty, 2017

17. Selvarajah E, Hooper G, Grabowski K, Frampton C, Woodfield TB, Inglis G. The rates of wear of X3 highly cross-linked polyethylene at five years when coupled with a $36 \mathrm{~mm}$ diameter ceramic femoral head in young patients. Bone Joint J 97-b(11): 1470, 2015 
18. Rajpura A, Board TN, Siney PD, Wynn Jones H, Williams S, Dabbs L, Wroblewski BM. A 28-year clinical and radiological follow-up of alumina ceramic-on-crosslinked polyethylene total hip arthroplasty. Bone \& Joint Journal 99-B(10): 1286, 2017

19. Adam P, Farizon F, Fessy MH. Dual mobility retentive acetabular liners and wear: surface analysis of 40 retrieved polyethylene implants. Orthop Traumatol Surg Res 100(1): 85, 2014 20. Boyer B, Neri T, Di Iorio A, Geringer J, Philippot R, Farizon F. The linear penetration rate is not relevant for evaluating wear of dual mobility cups: an explant study. Int Orthop 41(3): 599, 2017

21. Pineau V, Lebel B, Gouzy S, Dutheil JJ, Vielpeau C. Dual mobility hip arthroplasty wear measurement: Experimental accuracy assessment using radiostereometric analysis (RSA).

Orthop Traumatol Surg Res 96(6): 609, 2010

22. Martell J, Berdia S. Determination of Polyethylene Wear in Total Hip Replacements with Use of Digital Radiographs*, 1997

23. Takahashi Y, Shishido T, Yamamoto K, Masaoka T, Kubo K, Tateiwa T, Pezzotti G.

Mechanisms of plastic deformation in highly cross-linked UHMWPE for total hip componentsThe molecular physics viewpoint. Journal of the Mechanical Behavior of Biomedical Materials 42(Supplement C): 43, 2015

24. Miura Y, Hasegawa M, Sudo A, Pezzotti G, Puppulin L. In-vivo degradation of middle-term highly cross-linked and remelted polyethylene cups: Modification induced by creep, wear and oxidation. J Mech Behav Biomed Mater 51: 13, 2015

25. Bevill SL, Bevill GR, Penmetsa JR, Petrella AJ, Rullkoetter PJ. Finite element simulation of early creep and wear in total hip arthroplasty. J Biomech 38(12): 2365, 2005 
26. Waewsawangwong W, Goodman SB. Unexpected failure of highly cross-linked polyethylene acetabular liner. J Arthroplasty 27(2): 323.e1, 2012

27. Verdonschot N, Vena P, Stolk J, Huiskes R. Effects of metal-inlay thickness in polyethylene cups with metal-on-metal bearings. Clin Orthop Relat Res (404): 353, 2002

28. Pijls BG, Van der Linden-Van der Zwaag HM, Nelissen RG. Polyethylene thickness is a risk factor for wear necessitating insert exchange. Int Orthop 36(6): 1175, 2012

29. Penmetsa JR, Laz PJ, Petrella AJ, Rullkoetter PJ. Influence of polyethylene creep behavior on wear in total hip arthroplasty. J Orthop Res 24(3): 422, 2006

30. Oonishi H, Iwaki H, Kin N, Kushitani S, Murata N, Wakitani S, Imoto K. The effects of polyethylene cup thickness on wear of total hip prostheses. J Mater Sci Mater Med 9(8): 475, 1998

31. Lee PC, Shih CH, Chen WJ, Tu YK, Tai CL. Early polyethylene wear and osteolysis in cementless total hip arthroplasty: the influence of femoral head size and polyethylene thickness. J Arthroplasty 14(8): 976, 1999

32. Goebel P, Kluess D, Wieding J, Souffrant R, Heyer H, Sander M, Bader R. The influence of head diameter and wall thickness on deformations of metallic acetabular press-fit cups and UHMWPE liners: a finite element analysis. J Orthop Sci 18(2): 264, 2013

33. Devane PA, Horne JG. Assessment of polyethylene wear in total hip replacement. Clin Orthop Relat Res (369): 59, 1999

34. So K, Goto K, Kuroda Y, Matsuda S. Minimum 10-Year Wear Analysis of Highly CrossLinked Polyethylene in Cementless Total Hip Arthroplasty. J Arthroplasty 30(12): 2224, 2015 35. Shen FW, Lu Z, McKellop HA. Wear versus thickness and other features of 5-Mrad crosslinked UHMWPE acetabular liners. Clin Orthop Relat Res 469(2): 395, 2011 
36. Nashed RS, Becker DA, Gustilo RB. Are cementless acetabular components the cause of excess wear and osteolysis in total hip arthroplasty? Clin Orthop Relat Res (317): 19, 1995 37. Kelly NH, Rajadhyaksha AD, Wright TM, Maher SA, Westrich GH. High stress conditions do not increase wear of thin highly crosslinked UHMWPE. Clin Orthop Relat Res 468(2): 418, 2010

38. Haw JG, Battenberg AK, Huang DT, Schmalzried TP. Wear Rates of Larger-Diameter Cross-Linked Polyethylene at 5 to 13 Years: Does Liner Thickness or Component Position Matter? J Arthroplasty 32(4): 1381, 2017

39. Hamai S, Nakashima Y, Mashima N, Yamamoto T, Kamada T, Motomura G, Imai H, Fukushi JI, Miura H, Iwamoto Y. Comparison of 10-year clinical wear of annealed and remelted highly cross-linked polyethylene: A propensity-matched cohort study. J Mech Behav Biomed Mater 59: 99, 2016

40. Elfick AP, Hall RM, Pinder IM, Unsworth A. The effect of socket design, materials and liner thickness on the wear of the porous coated anatomic total hip replacement. Proc Inst Mech Eng H 215(5): 447, 2001

41. Korduba LA, Essner A, Pivec R, Lancin P, Mont MA, Wang A, Delanois RE. Effect of acetabular cup abduction angle on wear of ultrahigh-molecular-weight polyethylene in hip simulator testing. American Journal of Orthopedics (Belle Mead, NJ) 43(10): 466, 2014 


\section{Legend to Figures}

Figure 1. The linear femoral head penetration rate $(\mathrm{mm} /$ year) decreased following an exponential regression with $\mathrm{R}^{2}=0.999$.

Figure 2. The volumetric femoral head penetration rate $\left(\mathrm{mm}^{3} / y e a r\right)$ decreased following an exponential regression with $\mathrm{R}^{2}=0.986$.

Figure 3. Linear femoral head penetration (mm/year) extended to 15-years post-op using the exponential regression equation.

Figure 4. Dual mobility inner bearing material comparison of ceramic vs cobalt-chromium $(\mathrm{CoCr})$. The ceramic inner bearing had a significantly lower linear head penetration $(\mathrm{mm})$ up to three-years post-op $(\mathrm{p} \leq 0.001)$. 


\section{Linear Head Penetration Rate (mm/year)}

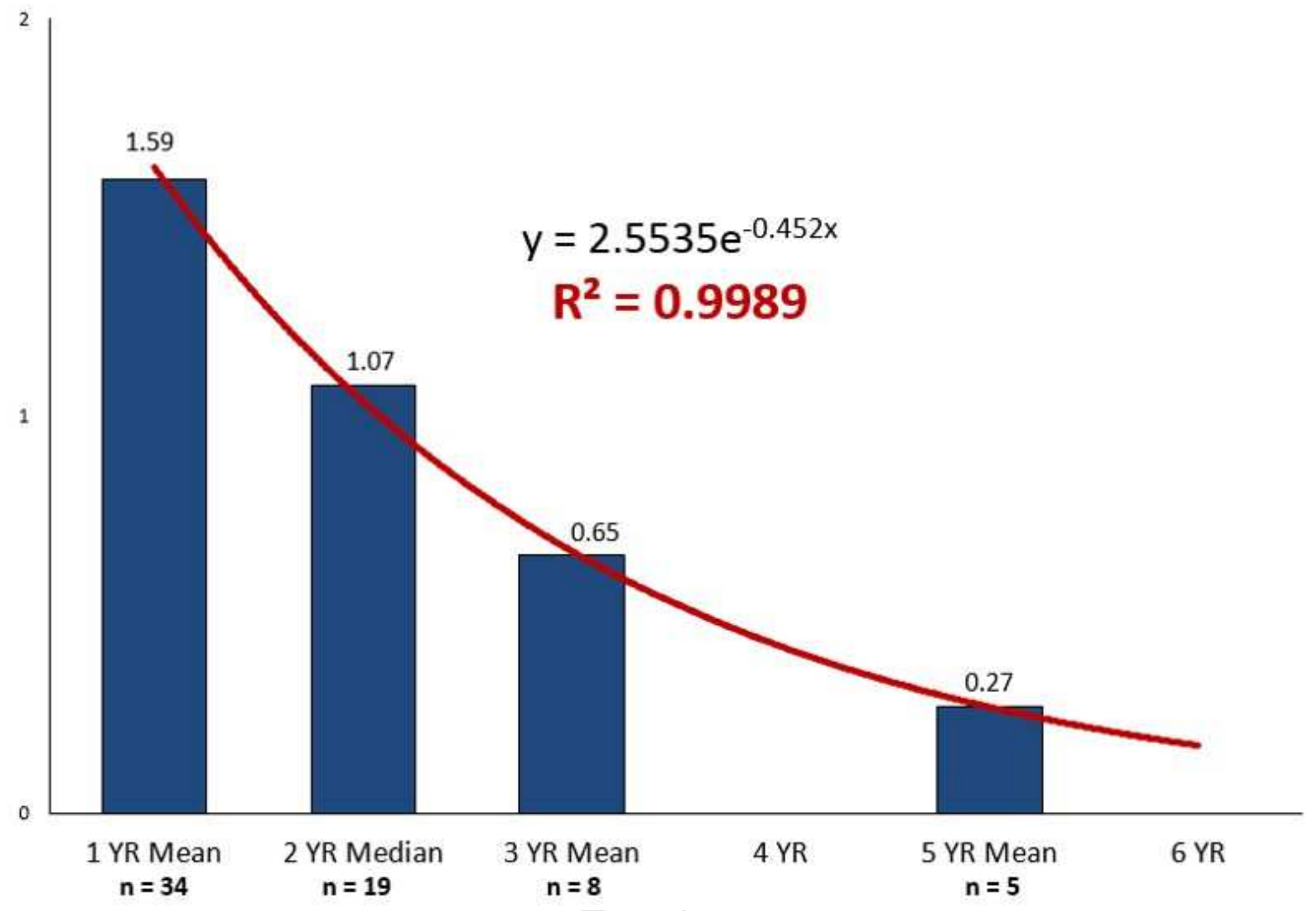


Volumetric Head Penetration Rate $\left(\mathrm{mm}^{3} /\right.$ year $)$

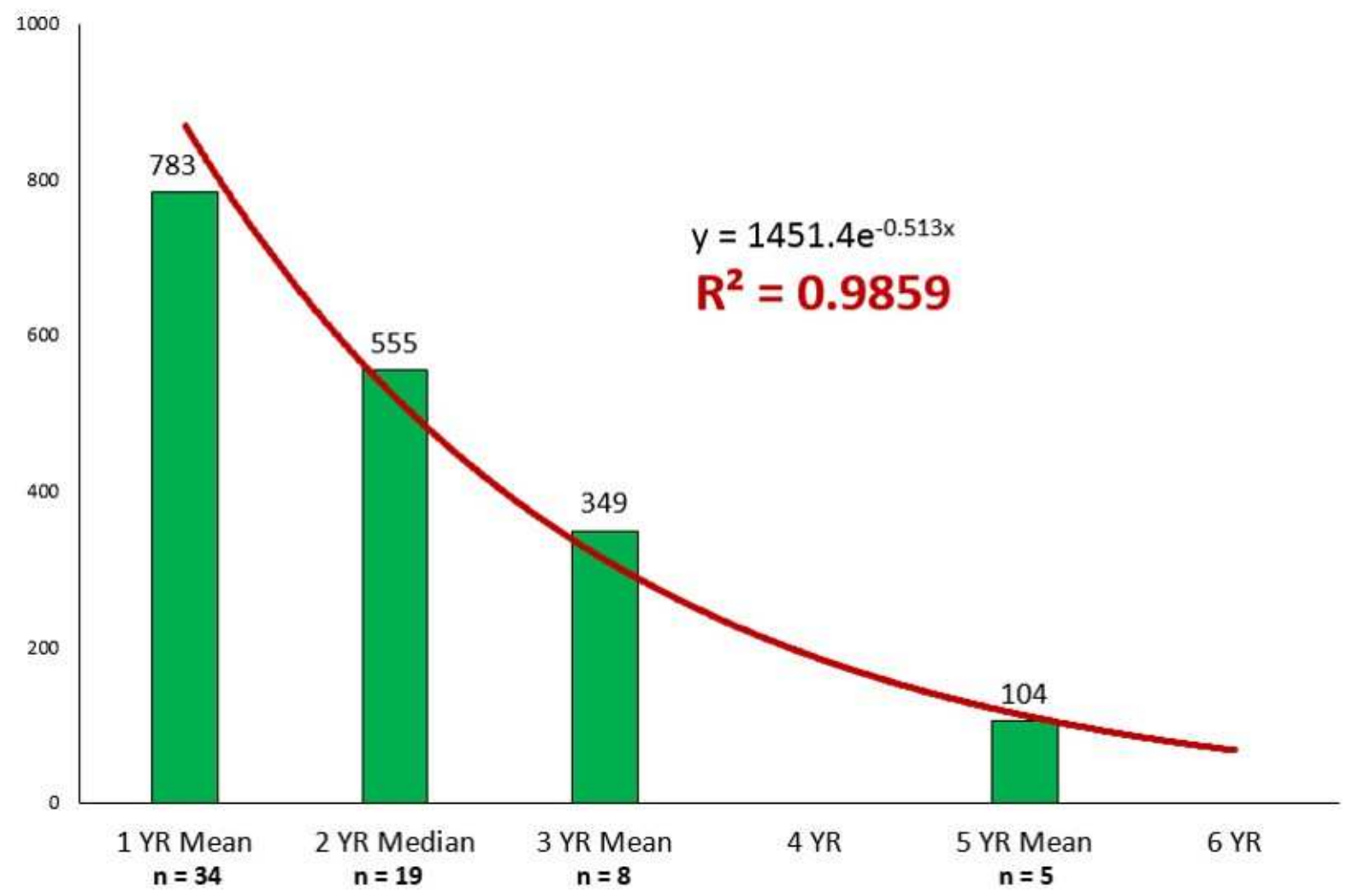




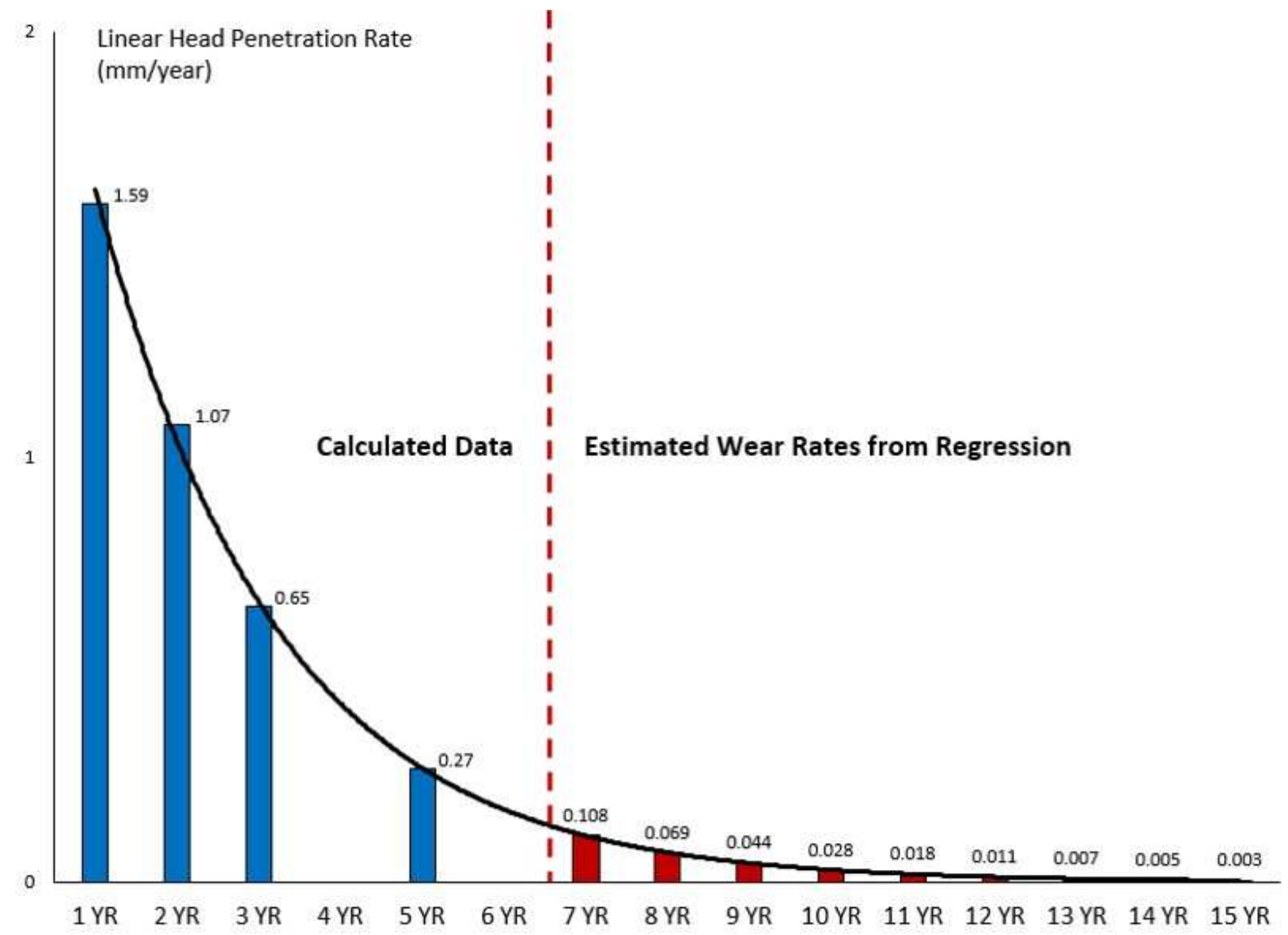




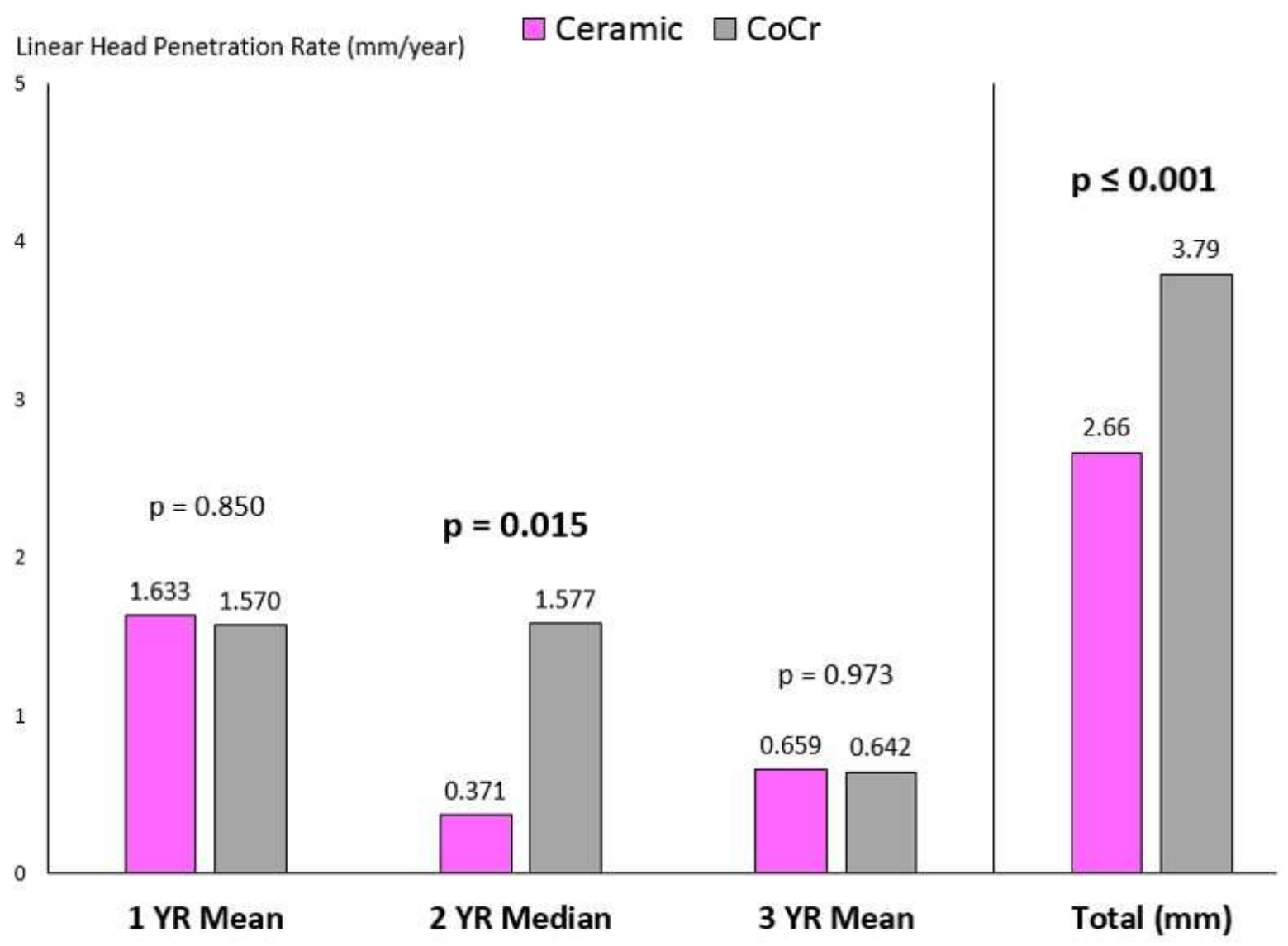




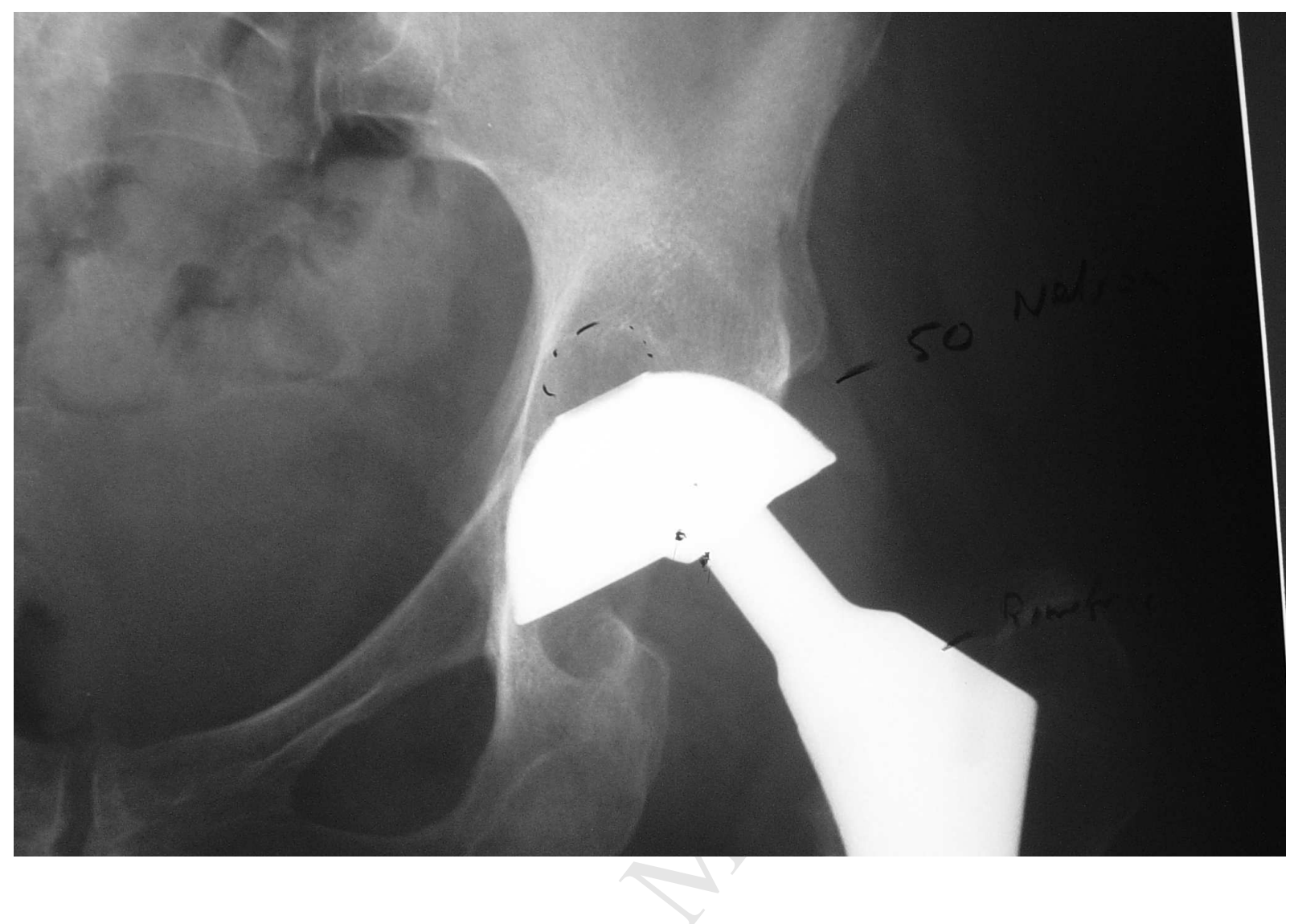

